\title{
The Design Concept of e-Decision Making Competence Based Self-Determination Learning On-Line System
}

\author{
Pi-Shan Hsu and Te-Jeng Chang
}

\begin{abstract}
Online learning becomes a popular and key role in modern education system. Comparing with traditional face-to-face learning, in online learning environment the main advantage is to create self-determination context for flexible learning. The e-decision-making refers to students' critical thinking, analysis/solution of problems, and the operation/assistant of information and e-systems. The purpose of this research is (1) to discuss the competence of computer science students majoring should attain; (2) to establish the indicators of e-decision making competence. This research uses literature review to define the term of "e-decision making". The analytic hierarchy process(AHP) proposed multiple criteria decision-making. In this platform, indicators creating are very importance. That is, electronic decision thinking improves the interaction between the thinking ability on issues and Information processing capabilities. This paper incorporates the concept of self-determination learning into creative learning. Information competency and information skills are employed to model the entire process of scientific invention in a step-by-step manner.
\end{abstract}

Index Terms-E-decision making, on-line system, self-determination learning.

\section{INTRODUCTION}

The online learning plays a key role in modern education system because of the progress of e-learning technology. In online learning environment, educators concern that how to motivate students effectively in order to lead them learn independently and achieve individual academic outcomes, which students and instructors also care about. In this situation, if there are four types of learning situated cognition, motivation, strategies for learning, cognitive resources, self-regulation. Indicators needs to pack four adaptable cognition packages individually that are with each redefinition of roles, the importance of taking risks, individual versus group orientation for self-determination, the importance of early experiences structure. Self-determination learning has been extensively use for training problems in universities and indicators and therefore finding predictors of electronic decision thinking satisfaction has become an important issue in colleges and universities to enhance students' critical ability and employability and

Manuscript received October 13, 2012; revised December 24, 2012. This work was supported in part by the Taiwan National Science Council (NSC 99-2511-S-254-001-MY3).

P. S. Hsu is with the Human Resource Development, Ching Kuo Institute of Management and Health, Keelung, Taiwan (e-mail: pshsu@ ems.cku.edu.tw).

T. J. Chang was with the Department of Industry Education at the National Taiwan Normal University, Taipei, Taiwan(e-mail tjmax950@yahoo.com.tw). competitiveness. Intrinsic motivation is an individual initiative, are autonomous self-determination, determined mainly by perceived autonomy and perceived competence affected from[1] nothing can be controlled by controlling aspect and informational aspect of the mechanisms affecting intrinsic motivation.[2]proposed self determination, perceived self-determination and self-perceived ability that the higher the intrinsic motivation will be enhanced, through the gradual internalizing and integrating will eventually be transformed into a self-determined by self motivated of actions or values. [1] integrated organism integration theory (OIT), its emphasis on intrinsic motivation and extrinsic motivation for the achievement of individual learning within the technology and integration, extrinsic motivation by self-the continuity of the decision to order, from low to high degree of external regulation, interjected regulation, indentified regulation, integrated regulation, the degree of autonomy of self-determined motivation to showing a continuous dimension, self-adjusting scale (SRQ-A) [3], [4].

Global economics' impetus relies on unceasingly digital system. The assessment and the demonstration of information communication technology (ICT) is the developmental priority in many higher and adult educational programs. [5], [6] pointed out: "Within the IT's explosion period, the communication science and technology had made a huge progress, and application of communication science and technology, which carries on the decision-making, the problem analysis, and the solution, has become the inevitable tendency in ICT world". In order to analyze the students' e-decision-making, [7], [8] pointed out: "the competence of the e-decision-making refers to students' critical thinking, the analysis/solution of problems, and the operation/assistant of information and e-systems". The literature analysis to draw a content of e-decision-making and to develop the draft of indicators of e-decision making competence. According that, the purposes of this research is 1) to discuss the competence of computer science students majoring should attain; 2) to establish the indicators of e-decision making competence.

\section{E-DECISION MAKING COMPETENCE BASED SELF-DETERMINATION LEARNING ON LINE SYSTEM}

Online learning environment is different from traditional face-to-face learning environment. Its main features are flexible in formats and texts, interesting, low-pressure, reusable, and instant in feedback and interaction. The benefits are not guaranteed but it is interesting that the research literature shows that online learning increase the abilities of decision-making, critical thinking[8], and higher level of intrinsic motivation[1]. The research results indicate that 
applying self-determination theory (SDT) on online learning environment is worth and its outcomes are what this study proposes to experiment on. In SDT the social agencies have great influences in social supports. It is evident that the social supports of online learning environment have a significant direct effect on self-determined motivation through the mediation of need satisfaction represented by autonomy, competence, and relatedness [9]. The methodological procedure adopted was to have the experimental group use the system, with the control group using conventional assessment. According to estimated effect size, the most significant indicators were reflection, self assessment, continuous improvement, goal setting, problem solving, data gathering, work and peer interaction. e-decision thinking competence. The following features is displayed in the student's real learning-outcome: motivational enhancement, fostering the power of decision making and selection (self-evaluating the learning outcome and establishing the learning objective) by [10], allowing students to develop high-level self-evaluation and decision-making skills, continuously check learning progress and promoting reflection as well as assessment of learning. [11] also claims concerning the need to accommodate individual requirements. In this context, learning-outcome evaluation is much easier than learning-process evaluation, largely owing to the latitude it affords for student participation. One has a working example of how information collection, selection, reflection, self-assessment and peer assessment can be regarded as the performance indicators for using portfolio assessment[12]. This impression is magnified when one considers how they may extend to self-assessment, self-improvement, responsibility, quality of works, reflection, creativity, data gathering, collaboration, resource The setting of the study are: 1) Information Engineering familiar with "self-determined learning" and "e-based decision-making ability to think," the expert 8,2) e-Learning systems expert with 8-bit, 3) Department of Computer Science industry experts and experienced teachers 8 . Research methods under this paper, the proposed open interviews with informal interviews of the outline and the development of a formal Delphi survey and the revised analytic hierarchy process (AHP) questionnaire as a research tool and the development of Science and Information Engineering online learning platform scale system development and evaluation, surveys the development of e-learning platform and evaluation factors. Specifically, research tools are the following: 1) Open interviews outline 2) Repair the formal Delphi survey and AHP questionnaire 3) Science and Information Engineering, online learning platform scale system development and evaluation. Data gathering A questionnaire on student's performance was created by summarizing references from literature review. The questionnaire was then refined after several reviews and discussions by four teachers and four field experts in order to ensure content validity. Finally, seven aspects in the questionnaire were derived from a focus discussion of the reviewers mentioned above. Regarding this study theoretical framework to discuss and build self-determined learning system prototype. The system will give students the design of the main questions to learn each load of the curve [13], so students can assess their skills through the curve, self-monitoring behavior, and in determining the curve, they can make to show independent performance and enhance their capacity [14].

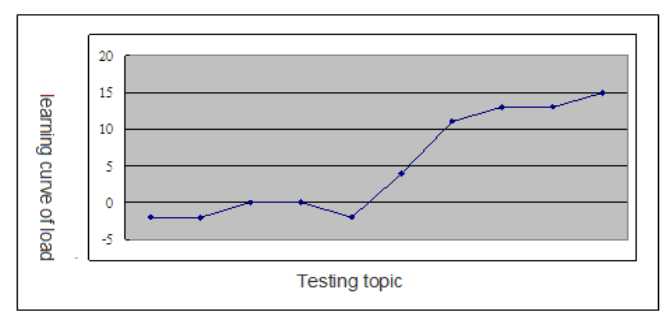

Fig. 1. The independent performance and enhance their capacity

Discussion of function, students can use the discussion area, so that between individuals and groups can have interaction, a sense of belonging. This study used the prototype system development method to develop a prototype system to study the establishment of the first prototype for testing the system, then according to teachers, students, engineers and re-fix the usage.

\section{SelF-DeterminAtion THEORY VS ONLINE LEARNING OUTCOME}

Internalization is important in SDT because it explains the way how individuals to be motivated in the way how they are supported by social contexts. It is also the process of taking in a value to higher level of intrinsic motivation is the concept of SDT[15]. A way how individuals take in a vale is to see how the contextual environment supports basic needs. The high level of needs satisfaction leads to the high level of self-determined behaviors in which positive learning outcomes are expected. To explicit the basic needs of SDT, it is expected to mention that human beings are growth-oriented organisms. The competence of the e-decision-making refers to students' critical thinking, the problem analysis/solution, and the operation/assistant of information and e-systems [7], [8]. The problem-solving is the combinational plan, whereas students used the knowledge and concepts they already learned to solve the problems and issues [16]. [17] thought that the question solution is a kind of learning process. Problem-solving competences, which include finding problems, analyzing currency, making right decision, implementing projects, and evaluating the conclusion, all should be categorized in higher thinking process [18]. The competence of the e-decision-making refers to students' critical thinking, the analysis/solution of problem, and the operation/assistant of information and e-systems [7], [8]. Hermeneutics methodology is mainly created by the researcher unceasing construction and the explanation, in order to construct importantly, representative decisive indicators [19]. This research uses the Hermeneutics methodology to construct the indicators. Hermeneutics methodology is mainly created by the researcher unceasing construction and the explanation, in order to construct importantly, representative decisive indicators [19].

\section{CONCLUSIONS AND Limitations}

In addition to the performance of assessment, the remaining 
indicators of students' performances have shown significant differences between information access capabilities, Information evaluation capacity, Information management capabilities, Ability to integrate information, IT innovation, Ability to communicate information. In terms of overall performance, groups differ markedly. This suggests that the use of the portfolio assessment system significantly affects the student's performance. The result coincides with the conclusion of most researchers that. Nevertheless, detailed performances were not identified in these previous studies. Although the performance of work has been enhanced, it is less significant than other performances. Striving to improve a student's computer skills and knowledge is recommended as a means to this end other recommendations. Particularly noteworthy are validity and reliability, time consumption, peer-assessment ability and technology usage. They are often limited to assessment and reflection would promote students' learning outcomes and be beneficial to students' reflection processes. In the final analysis, this study has constructed some grounds from which to argue that while the interactive effects of teaching strategies and assessment methods on learning are certainly multifarious, they remain amenable to empirical investigation, and as such, may ultimately be harnessed to the setting of educational policy goals. This research focuses on the development of e-decision making indicators. We believe the information of teachings and contents can be variable, but the different teaching and contents should follow the same pattern of indicators. Therefore, this research tries to provide a concrete, reliable accomplishment, and we wish to let the indicators to be a target for school to raise students' ability in e-decision making. According to the literature review and the Hermeneutics methodology, the researchers have revised the indicators into the final version, which includes seven capabilities (information definition, access, assessment, management, conformity, innovation and dissemination). Each capability has its followed indicators the finding of the research shows the indicators have reached the experts' consistent level, and the reliability of each indicator's importance also has reached the superior level.

\section{ACKNOWLEDGMENT}

This research was supported by the Taiwan National Science Council (NSC 99-2511-S-254-001-MY3).

\section{REFERENCES}

[1] C. Chen and J. Jang, "Motivation in online learning: Testing a model of self-determination theory," Computer in Human behavior, vol. 26, pp. 741-752, 2012

[2] D. McAlpine. (Jan 2012). Assessment and the Gifted. Tall Poppies. 25(1). [Online]. Available: http://www.tki.org.nz/r/gifted/pedagogy/portfolio_e.php.

[3] E. D. Gagné, The cognitive psychology of school learning, Boston: Little, Brown and Company, 1985.

[4] F. H. Briggs, "Problem solving in diabetes self-management: A model of chronic illness self-management behavior," Annals of Behavioral Medicine, vol. 25, no. 3, pp. 182-193, 2003.

[5] H. Ou, Educational test and assessment, Taipei: Shin-Lee Press, 2004.

[6] J. Clark, "It governance: Determining who decides," ECAR Research Bulletin, vol. 24, pp. 1-13, 2005.

[7] J. Dewey, How we think, New York: D. C. Heath, 1933.

[8] L. Deci and M. Ryan, "Gagné M, Leone D, Usunov J, and Kornazheva B. Need satisfaction, motivation, and well-being in the work organizations of a former eastern bloc country: Across- cultural study of self-determination," Personality and Social Psychology Bulletin vol. 27, no.8, pp. 930-942, 2001.

[9] L. Deci and M. Ryan, "Self-determination theory: When mind mediates behavior," The Journal of Mind and Behavior, vol. 1, no. 1, pp. 33-43, 1980 .

[10] L. Deci and M. Ryan, "The "what" and the "why" of goal pursuits: Human needs and the self-determination of behavior," Psychological Inquiry, vol. 11, pp. 227-268, 2000.

[11] L. Deci and M. Ryan, Intrinsic motivation andsSelf-determination in human behavior, Plenum Press, 1985.

[12] M. Ryan and L. Deci, "Overview of self-determination theory: An organismic dialectical perspective," in L. Deci \& M. Ryan (eds.), Handbook of self-determination research, Rochester, NY: University of Rochester Press, pp. 3-33, 2002.

[13] P. S. Hsu and T. J. Chang, "A new process phase diagnostic technique - Visualized interface for diagnosing learning progress," in Q. Jin (Eds.), Distance Education Environments and Emerging Software Systems: New Technologies, IGI Global Press, pp.138-150, 2011.

[14] P. S. Hsu, T. J. Chang and M. H. Wu, "A new diagnostic mechanism of instruction: A dynamic, real-time and non-interference quantitative measurement technique for adaptive e-learning," International Journal of Distance Education Technologies, vol. 7, no. 3, pp. 85-96, 2009.

[15] P. Weill and W. Ross, It governance - how top performers manage it decision rights for superior results, Harvard Business School Press, 2004.

[16] R. Z. Hong, "The application of Hermeneutics methodology in policy making," Secondary education, vol. 48, no. 5, pp. 39-47, 1997.

[17] S. Albitz, "The "what" and "who" of information literacy and critical thinking in higher education," Libraries and the Academy, vol. 7, no. 1, pp. 97-109, 2007.

[18] T. Putnam and H. Borko, "What do new views of knowledge and thinking has to say about research on teacher learning?" Educational Researcher, vol. 29, no. 1, pp. 4-15, 2000.

[19] Y. Kuo, Educational test and assessment, Taipei: Chin-Hau Press, 2004.

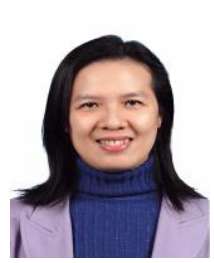

Dr. Pi-Shan Hsu is currently an associate professor of Human Resource Development at Ching Kuo Institute of Management and Health in Taiwan. Her research interests include dynamic assessment technology, learning diagnostic techniques, adaptive e-learning, and Creativity. She received Ph.D. in the Department of Industry Education at the National Taiwan Normal University (NTNU) and the Master of Art degree in teacher education from the Eastern Michigan State University, USA. She has been a teacher more than 18 years. In the period of her research, she has led several research teams of the national projects from National Science Council which focuses on creativity scales and assessment, mental operation process of technological creativity, innovation, curriculum development for adaptive e-learning and earning diagnostic technique development. She is the reviewer of International Journal of Educational Development (SSCI Journal) and the section chair of several international conferences. She received the best achievement of vocational education from Taiwan government because of her significant contribution in vocational education in past decades and her outstanding research efforts.

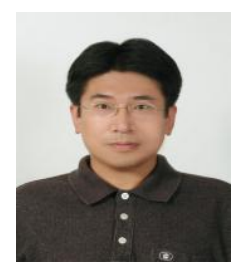

Dr. Te-Jeng Chang is the corresponding author of this article. He received Ph.D. degree in the Department of Industry Education at the National Taiwan Normal University (NTNU). His research interests include dynamic assessment technology, cognitive load, learning diagnostic techniques, adaptive e-learning, and organizational learning. $\mathrm{He}$ received the Master of Science degree in mechanical engineering from the University of Michigan, USA. Since 1990, he has been worked in mechanical manufacturing industry more than 20 years and been the executive operation officer for several global enterprises. The practical experiences in both applying e-learning for human resources training and constructing organizational learning environment and system enlighten him in related researches. 